\title{
La fiebre del Nilo occidental: una enfermedad emergente en México
}

$\mathrm{E}$ 1 virus del Nilo occidental (VNO) pertenece a la Familia Flaviviridae, género flavivirus, donde se ubican otros virus que causan enfermedades en humanos como la encefalitis japonesa, fiebre amarilla, encefalitis de San Luis, encefalitis del Valle Murray, encefalitis transmitida por garrapatas y fiebre por dengue. La mayoría de estos virus son transmitidos a sus huéspedes a través de la picadura de mosquitos vectores, y muchos tienen tropismo por el sistema nervioso central.

El genoma de los flavivirus está constituido por una cadena sencilla de RNA de polaridad positiva, tienen una envoltura de lípidos y están constituidos por tres proteínas estructurales. ${ }^{1}$

El VNO se aisló por primera vez de una paciente febril en el Distrito West Nile (Nilo occidental) en Uganda, Africa, en 1937. ${ }^{2}$ Estudios posteriores demostraron la presencia de este virus en Africa, Asia y Europa, donde anualmente ocurren casos en humanos y en diversos animales.

La mayoría de las infecciones causadas por el VNO son asintomáticas, sin embargo, alrededor de $20 \%$ de las personas infectadas desarrollan la fiebre del Nilo occidental (FNO), que clínicamente se caracteriza por fiebre, cefalea, dolor de garganta, mialgias, artralgias, debilidad muscular, conjuntivitis, rash, linfadenopatía, náusea, anorexia, dolor abdominal y diarrea, las cuales apa- recen después de un periodo de incubación de 3- 6 días. Aproximadamente $1 \%$ de los casos pueden presentar complicaciones neurológicas con datos de encefalitis, meningitis aséptica o meningoencefalitis (que en conjunto se denomina enfermedad neuroinvasiva), y que se manifiestan por confusión, alteraciones de la conciencia, somnolencia, temblores, alteración en los reflejos, convulsiones, parálisis flácida o coma. La tasa de letalidad en los pacientes con enfermedad neuroinvasiva es de 5-14\%.

Actualmente no hay vacunas para uso en humanos ni medicamentos anti-virales específicos, el tratamiento es sintomático y de apoyo, particularmente en pacientes que tienen complicaciones respiratorias. ${ }^{3-8}$ La única vacuna disponible es para uso en caballos.

La infección natural por el VNO ocurre a través de la picadura de diversas especies de mosquitos, particularmente del género Culex sp; sin embargo, pueden ocurrir infecciones por otras vías como la transfusión de sangre, transplante de órganos, vía transplacentaria, por medio de la leche materna y la exposición accidental en personal médico y de laboratorio.

El diagnóstico de la FNO se hace mediante la detección de anticuerpos contra el VNO en el suero o en el líquido cefalorraquídeo (por ejemplo ELISA de captura, anticuerpos neutralizantes, etcétera), por el aislamiento del virus en cultivo de células, por la detección del genoma del virus (Transcriptasa ReversaReacción en Cadena de la Polimerasa, RT-PCR), o mediante inmunohistoquímica en tejidos. No obstante, debido a que los anticuerpos contra el VNO tienen reacciones cruzadas con otros virus de la misma familia, se requieren técnicas serológicas más sensibles y específicas; la técnica de ELISA de bloqueo ${ }^{9}$ se utiliza para la detección de anticuerpos en aves y caballos infectados; la determinación de anticuerpos neutralizantes a través de la técnica de reducción de placa lítica en cultivo de células se usa como prueba confirmatoria. Actualmente existen varios procedimientos comerciales (kits) para la detección de anticuerpos contra el VNO, cuya utilidad como herramienta de diagnóstico requiere ser evaluada.

El VNO se puede mantener en un ciclo silvestre en animales a través de la picadura de mosquitos (ciclo silvestre), no obstante, la presencia de mosquitos con preferencias alimenticias por el hombre y animales domésticos puede permitir la diseminación del virus en zonas rurales y urbanas.

Hasta finales de la década de 1990 se desconocía la existencia del VNO en el continente americano, sin embargo, en el verano de 1999 se reportaron en Nueva York, Estados Unidos de América (EUA), los pri- 
meros casos en humanos de FNO con afectación neurológica; casi simultáneamente se reportaron aves muertas en la misma región, de las cuales posteriormente se identificó el VNO que afectó a los humanos. La infección se extendió por todo el territorio norteamericano y en algunas provincias de Canadá; México estuvo en riesgo de la introducción del virus desde su aparición en EUA, pero no fue sino hasta el año 2002 cuando se reportaron los primeros casos en aves y caballos, en algunos estados ubicados en la frontera norte y en la península de Yucatán; recientemente se han reportado casos de FNO en El Caribe y Centroamérica. A la fecha no se han reportado casos en países de Sudamérica, aunque existe el riesgo de la introducción del VNO debido a su capacidad de infectar a una diversidad de aves migratorias, animales domésticos y silvestres, y mosquitos vectores.

Por su impacto en la salud pública, la FNO se considera una enfermedad emergente en el continente americano; solamente en los EUA durante el periodo de 1999-2003 se reconocieron 9100 casos en humanos. ${ }^{10}$

La mayoría de los casos fatales han ocurrido en hombres mayores de 50 años de edad; la transmisión del virus en los EUA tiene un patrón estacional y muchos casos se reportan entre julio y septiembre. Durante el periodo de 1999-2003 ocurrieron 19886 casos en caballos y alrededor de 49 especies de mosquitos (principalmente Culex sp) son susceptibles a la infección.

Los estudios realizados en aves indican que más de 225 especies, particularmente los cuervos, son susceptibles a la infección. Entre estas especies destacan también las aves migratorias, que pueden tener un papel relevante en la diseminación del virus. Hay evidencia de que otros animales pueden ser infectados por el VNO como ardillas, perros, gatos, borregos, conejos, murciélagos, cocodrilos, tortugas y caimanes, entre otros.

A partir del año 2000 se estableció oficialmente en México la vigilancia epidemiológica para el VNO, particularmente en regiones prioritarias (el Golfo de México y la Península de Yucatán, por ejemplo). Hasta la fecha se han hecho estudios serológicos que indican la presencia del virus en humanos, caballos, aves (migratorias y residentes) y mosquitos. El primer reporte sobre la circulación del VNO en México se publicó en el año 2002 en dos estudios serológicos independientes que se hicieron en caballos en Coahuila y Yucatán, que mostraron prevalencias de $62.5 \%$ y $1.2 \%$, respectivamente. ${ }^{11,12}$ Posteriormente se llevó a cabo un estudio más amplio en caballos de otras regiones del país que confirmó la presencia del VNO en México. En el año 2003 se reportó el aislamiento del VNO de un cuervo (Corvus corax) muerto en el parque ecológico Yumká de Villahermosa, Tabasco; la secuencia del genoma de este virus mostró una divergencia genética diferente a la de otros virus aislados en el continente americano. ${ }^{13}$ Se han reportado seis casos humanos con diagnóstico confirmado de infección por el VNO en los estados de Chihuahua, Nuevo León y Sonora; tres fueron clasificados como FNO y tres presentaron encefalitis; hasta ahora no se han reportado casos fatales por esta causa. ${ }^{14,15}$

El riesgo más importante de dispersión del virus a otras regiones del continente americano es a través de aves migratorias infectadas; en efecto, una gran diversidad de aves migratorias se han visto implicadas en la diseminación de otros arbovirus. ${ }^{16}$ La Secretaría de Salud de México (a través del Centro Nacional de Vigilancia Epidemiológica) y otras dependencias del gobierno federal han fortalecido las acciones de vigilancia epidemiológica en los sitios donde anualmente llegan aves provenientes del continente americano, principalmente en las entidades ubicadas en el Golfo de México y la Península de Yucatán. Estudios recientes sugieren la presencia del VNO en aves migratorias y residentes en esta última región. ${ }^{17}$

No se ha realizado una evaluación del impacto económico de la infección por el VNO en caballos y en otros animales domésticos y silvestres $^{18,19}$

Las alteraciones neurológicas en pacientes febriles puede ser un indicador de infección por el VNO aunado a la presencia del virus en aves, animales y mosquitos. Además, se sabe que la presencia de mosquitos y aves infectadas generalmente preceden a la aparición de casos en humanos y en otros animales.

Debido a que el VNO está clasificado como un patógeno de alto riesgo, su manejo requiere el uso de instalaciones de seguridad biológica de nivel 3, particularmente cuando el virus se mantiene en cultivo de células o en animales de experimentación; los procedimientos serológicos para la detección de anticuerpos en suero o en líquido cefalorraquídeo, aunque de menor riesgo para el personal de laboratorio, requieren el uso de gabinetes de bioseguridad y cumplir con las medidas de seguridad que recomiendan los Centros para el Control y Prevención de Enfermedades (CDC) de los EUA y la Secretaría de Salud de México, respecto de la toma de muestras, su manejo, envío y conservación. ${ }^{20,21}$

La introducción del VNO a zonas endémicas para dengue (la mayoría de los países de El Caribe, Centro y Sudamérica) puede estar asociada con cierto grado de protección ya que una amplia población tiene anticuerpos contra el virus dengue que podrían conferir protección cruzada temporal contra el $\mathrm{VNO}$, e inclusive podrían asociarse con casos menos severos; de todas 
maneras, no se puede descartar la participación de los anticuerpos de reacción cruzada en la aparición de casos severos, como se ha descrito en pacientes con fiebre hemorrágica por dengue.

La presencia del VNO en México hace necesaria una mayor difusión, al personal de los servicios de salud, de los aspectos básicos del agente causal, de la enfermedad, de los mosquitos vectores ${ }^{22}$ y de los reservorios, ${ }^{23-25}$ que coadyuven a realizar un mejor diagnóstico, establecer un tratamiento oportuno y adecuado de los pacientes, reportar oportunamente los casos y mejorar las medidas de prevención y control. Asimismo, es importante fortalecer la colaboración interinstitucional e intersectorial y el apoyo internacional. Hoy más que nunca es necesario fortalecer la infraestructura para desarrollar trabajos de investigación en este campo que incluyan la construcción de laboratorios de alta seguridad biológica para el manejo del VNO y otros agentes patógenos, la formación de recursos humanos y la realización de cursos de actualización y de entrenamiento técnico.

\section{Dr en C Celso Ramos, MC Jorge Abelardo Falcón Lezama. Departamento de Arbovirus Centro de Investigaciones sobre Enfermedades Infecciosas Instituto Nacional de Salud Pública} Cuernavaca, M orelos, M éxico

\section{Referencias}

1. Monath TP, Heinz FX. Flaviviruses. En: Fields B. Virology. $3^{\text {rd }}$ ed. N ueva York (N Y): A cademic Press; 1996: 961-1034.
2. Smithburn KC, Hughes TP, Burke AW, Paul JH. A neurotropic virus isolated from the blood of a native of $U$ ganda. Am JTrop Med 1940; 20:471-492.

3.T sai T, Popovici F, Cernescu C, Campbell G, $\mathrm{N}$ edelcu $\mathrm{N}$. W est $\mathrm{N}$ ile encephalitis epidemic in southeastern Romania. Lancet 1998; 352:767771.

4. Chowers MY, Lang R, N assar F, Ben-D avid D, Giladi M, Rubinshtein E et al. C linical characteristics of the W est $\mathrm{N}$ ile Fever outbreak, Israel, 2000. EID 2001; 7(4): 675-678.

5. N ash D, Mostashari F, Fine A, Miller J, 0 'Leary $D$, Murray $K$ et al.The outbreak of W est $N$ ile virus infection in the $\mathrm{N}$ ew York City area in 1999. N Engl J Med 2001;344:1807-1814. 6.W eiss D, C arr D, Kellachan J,Tan C, Phillips M, Bresnitz $E$ et al. C linical findings of W est $\mathrm{N}$ ile virus infection in hospitalized patients, $\mathrm{N}$ ew York and $\mathrm{N}$ ew Jersey, 2000. Emerg Infect $\mathrm{D}$ is 2001: 7(4): 654-658.

7. Petersen L, Marfin A.W est N ile Virus:A primer for the clinician. Annals of Internal Medicine 2003; 137; 173-179.

8. Sejvar JJ, Leis AA, Stokic DS,Van Gerpen JAV, Marfin AA, W ebb $R$ et al.A cute flaccid paralysis and $W$ est $N$ ile virus infection. Emerg Infect $D$ is 2003; 9(7): 788-793.

9. Blitvich BJ, Marlene N L, Hall RA, Calisher $\mathrm{CH}$ Bowen RA, Roehring, JT et al. Epitope blocking enzyme-linked immunosorbent assay for the detection of serum antibodies to $W$ est $N$ ile virus in multiple avian species. J Clin Microbiol 2003; 41:1041-1047.

10. Centers for Disease Control and Prevention. Summary of W est N ile Virus activity in the United States, 2003. Disponible en: http:// www.cdc.gov/ncidod/dvbid/westnile/conf/ppt/ Hayes_1_04.ppt. [2004 junio 7].

11. Blitvich BJ, Fernández-Salas I, ContrerasCordero JF, Marlenee N L, González-Rojas JI, Komar $N$ et al. Serologic evidence of W est $N$ ile virus infection in horses, Coahuila State, Mexico. Emerg Infect D is 2003; 9(7):853-856.

12. Loroño-Pino MA, Blitvich BJ, Farfán-Ale JA, Puerto $\mathrm{Fl}$, Blanco JM, Marlenee $\mathrm{NL}$ et al. Serologic evidence of W est $N$ ile Virus infection in horses, Yucatan State, Mexico. Emerg Infect $D$ is 2003; 9(7): 857-859.

13. Estrada-Franco JG, N avarro-López $R$, Beasley DW C, C offey L, C arrara AS, Travassos da Rosa $\mathrm{A}$ et al.W est $\mathrm{N}$ ile Virus in Mexico: Evidence of widespread circulation since July 2002. Emerg Infect D is 2003: 9(12): 1602-1607.
14. Boletín de Epidemio logía, Semana 53, 2003. Dirección General de Epidemiología. Disponible en: http://www.dgepi.salud.gob.mx/boletin/2003/ sem53/pdf/cua8.pdf. [2004 junio 7].

15. Boletín de Epidemio logía, Semana 34, 2004.

Dirección General de Epidemiología. Disponible en: http://www.dgepi.salud.gob.mx/boletin/2004/ sem34/pdf/cua8.pdf. [2004 septiembre 21]

16. Marra, PP, G riffin SM, McLean RG.W est N ile virus and wild life. BioScience 2004; 54: 293-402. 17. Farfán-Ale JA, Blitvich BJ, Loroño-Pino MA, Marlenee N L, Rosado-Paredes EP, García-Rejón JE. Longitudinal studies of W est $\mathrm{N}$ ile virus infection in avians,Yucatán State, México.VectorBorne Zoonotic Dis 2004. En prensa.

18. Steinman A, Banet-N oach C, Tal S, Levi O, Simanov $L$, Perk $S$ et al. West $N$ ile virus infection in crocodiles. Emerg Infect $D$ is 2003; 9: 887-889. 19. Miller DM, Mauel MJ, Baldwin C, Burtle G, Ingram $D$, Hines II ME et al. W est $N$ ile virus in farmed alligators. Emerg Infect D is 2003; 9: 794799.

20. Centers for Disease Control and Prevention. Instructions for sending diagnostic specimens for serology by the DVBID Arbovirus Diagnostic Laboratory. D isponible en: http://www.cdc.gov/ncidod/dvbid/westnile/ lab_guidance.htm. [2004 junio 16].

21. Centro $\mathrm{N}$ acional de Vigilancia

Epidemiológica. Manual para toma de muestra en equinos y aves. Disponible en: http:// www.cenave.gob.mx/von/. [2004 junio 16]. 22. $\mathrm{N}$ asci RS, W hite DJ, Stirling $\mathrm{H}, \mathrm{O}$ liver J, Thomas J. D aniels TJ et al.W est $N$ ile virus Isolates from mosquitoes in N ew York and $\mathrm{New}$ Jersey, 1999. Emerg Infect D is 2001; 7(4): 626663.

23. Rappole JH, Derrickson SR, Hubalek Z. Migratory birds and spread of W est N ile virus in the western hemisphere. Emerg Infect $D$ is 2000; 6(4): 319-328.

24. Eidson M, Kramer L, Stone S, HagiwaraY, Schmit, S, The N ew York State W est N ile Virus Avian Surveillance Team. D ead bird surveillance as an early warning system for W est $N$ ile virus. Emerg Infect D is 2001; 7(4): 631-635.

25. Langevin $S A$, Bunning $M, D$ avis $B, K$ Komar N . Experimental infection of chickens as candidate sentinels for W est $N$ ile virus. Emerg Infect $D$ is 2001; 7(4): 726-729. 